\title{
Methods and Research for Multi-Component Cutting Force Sensing Devices and Approaches in Machining
}

\author{
Qiaokang Liang ${ }^{1,2, *}$, Dan Zhang ${ }^{3,4, *}$, Wanneng Wu ${ }^{1,2}$ and Kunlin Zou ${ }^{1,2}$ \\ 1 College of Electric and Information Technology, Hunan University, Changsha 410082, China; \\ wuwanneng@hnu.edu.cn (W.W.); kunlin@hnu.edu.cn (K.Z.) \\ 2 State Key Laboratory of Advanced Design and Manufacturing for Vehicle Body, Hunan University, \\ Changsha 410082, China \\ 3 School of Mechanical, Electronic and Control Engineering, Beijing Jiaotong University, Beijing 100044, China \\ 4 Department of Mechanical Engineering, York University, Toronto, ON M3J 1P3, Canada \\ * Correspondence: qiaokang@hnu.edu.cn (Q.L.); dan.zhang@lassonde.yorku.ca (D.Z.); \\ Tel.: +86-731-8882-2224 (Q.L.); +1-416-736-2100 (ext. 44049) (D.Z.)
}

Academic Editor: Vittorio M. N. Passaro

Received: 18 August 2016; Accepted: 11 November 2016; Published: 16 November 2016

\begin{abstract}
Multi-component cutting force sensing systems in manufacturing processes applied to cutting tools are gradually becoming the most significant monitoring indicator. Their signals have been extensively applied to evaluate the machinability of workpiece materials, predict cutter breakage, estimate cutting tool wear, control machine tool chatter, determine stable machining parameters, and improve surface finish. Robust and effective sensing systems with capability of monitoring the cutting force in machine operations in real time are crucial for realizing the full potential of cutting capabilities of computer numerically controlled (CNC) tools. The main objective of this paper is to present a brief review of the existing achievements in the field of multi-component cutting force sensing systems in modern manufacturing.
\end{abstract}

Keywords: multi-component force sensing system; in-process measurement of cutting force; sensors for unmanned machining

\section{Introduction}

Unmanned machining centers such as Computer Numerical Control (CNC) machines are commonly used in manufacturing industries, allowing more accurate and quick fabrication $[1,2]$. As demands for higher quality, productivity, reliability, and efficiency level of manufacturing processes grow, reliable and effective sensing systems for CNC machines to monitor and inspect the cutting process and the condition of cutting tools have become necessary [3-8]. An unmanned machining center equipped with an automated cutting process monitoring system enables higher efficiency of equipment utilization, hence realizes significant manufacturing cost reductions. Among the variety of information provided by the monitoring system, cutting force are essential for achieving the elementary physical mechanics and dynamics of cutting processes.

Force sensing systems have presented themselves in a bewildering variety of industrial automation equipment since the late 1970s [9-12].

In recent years, cutting force sensing systems have been widely used as the most effective method to identify or monitor the dynamic behavior of cutting processes and the condition of cutting tools. Generally, force sensing systems used in automated machining processes can be divided into the following categories according to their functions: 
(a) Characterizing, modeling and optimizing the cutting process. Understanding the metal cutting mechanism such as effects of cutting variables on the cutting force, and then enabling the process planner to decide the optimal cutting conditions such as the cutting speed and feed rate.

(b) Monitoring the cutting tool condition such as cutter deflection and breakage. Predicting the real-time tool wear and tool failure. Analyzing the stresses of the cutter and machine tool. Verifying the conformity of dimensions, surface location error and surface finish to its geometric tolerances.

(c) Detecting the chatter vibrations and stability of the cutting process, providing information useful for mechanical design of cutters, machine tools and their spindle bearings.

In general, the various cutting force sensing systems can be categorized into either indirect or direct methods (Table 1). The indirect sensing approaches detect related parameters that change to some degree with cutting force such as spindle motor current, voltage, acceleration, acoustic emission, and vibration, etc. [13-22]. On the other hand, the direct sensing approaches are those that employ specific effects caused directly by cutting force. Specifically, these direct effects include mechano-magnetic, mechano-electric, and mechano-optic conversions, etc. [23-29]. Although the direct measuring approaches are easy to implement and can yield more accurate measurement results, the limitations such as low reliability, high cost, and fragility to overload, etc. prevent such methods from being applied in machine shops $[30,31]$. 
Table 1. Intrinsic transduction techniques for cutting force measurement [9].

\begin{tabular}{|c|c|c|c|c|c|}
\hline Measurement Type & Sensing Principle & Macroscopic Description & Advantages & Disadvantages & Typical Development \\
\hline \multirow{2}{*}{ Indirect approach } & Current & $\begin{array}{l}\text { Current consumption of the } \\
\text { driving motors of the } \\
\text { machine tool }\end{array}$ & $\begin{array}{l}\text { - } \quad \text { easier to achieve } \\
\text { - }\end{array}$ & $\begin{array}{l}\text { - } \quad \text { time-consuming } \\
\text { - } \quad \text { without consideration of the frictional } \\
\text { behavior of the machine tools }\end{array}$ & [32] \\
\hline & Voltage & $\begin{array}{l}\text { Command voltages of } \\
\text { magnetic bearings }\end{array}$ & $\begin{array}{l}\text { - } \quad \text { wide bandwidth (up to } 4 \mathrm{kHz} \text { ) } \\
\text { - } \quad \text { easy to conversion and processing }\end{array}$ & $\begin{array}{l}\text { - } \quad \text { Limited to stable conditions } \\
\text { - } \\
\text { electromagnetible to } \\
\text { - } \quad \text { requires magnetic bearing presence }\end{array}$ & [15] \\
\hline \multirow{4}{*}{ Direct approach } & Strain gauge & $\begin{array}{l}\text { Change in resistance due to } \\
\text { cutting force }\end{array}$ & $\begin{array}{ll}\text { - } & \text { simple construction } \\
\text { - } & \text { high and adjustable resolution } \\
\text { - } & \text { high reliability }\end{array}$ & $\begin{array}{ll}\text { - } & \text { higher power consumption } \\
\text { - } & \text { rigid and fragile } \\
\text { - } & \text { scarce reproducibility } \\
\text { - } & \text { contradictions between flexibility } \\
\text { - } & \text { and sensitivity } \\
\text { narrow frequency bandwidth }\end{array}$ & [22] \\
\hline & Capacitive & $\begin{array}{l}\text { Change in capacitance due } \\
\text { to cutting force }\end{array}$ & $\begin{array}{l}\text { - } \quad \text { high sensitivity and resolution } \\
\text { - } \quad \text { long-time stability } \\
\text { - }\end{array}$ & $\begin{array}{ll}\text { - } & \text { temperature sensitive } \\
\text { - } \quad \text { stray capacitance } \\
\text { - } \quad \text { Edge effect }\end{array}$ & [21] \\
\hline & optoelectronic & $\begin{array}{l}\text { Change in refractive index } \\
\text { due to cutting force }\end{array}$ & $\begin{array}{ll}\text { - } & \text { good reliability } \\
\text { - } & \text { wide measurement range } \\
\text { - } & \text { good adaptability to environment }\end{array}$ & $\begin{array}{l}\text { - } \quad \text { non-conformable } \\
\text { - } \quad \text { hard to construct dense arrays }\end{array}$ & [23] \\
\hline & Piezoelectric & $\begin{array}{l}\text { Generation of surface } \\
\text { charge due to cutting force }\end{array}$ & $\begin{array}{l}\text { - high frequency response and high } \\
\text { dynamic range } \\
\text { - } \quad \text { higher accuracy and } \\
\text { finer resolution } \\
\text { - high sensitivity and stiffness }\end{array}$ & $\begin{array}{l}\text { - } \quad \text { charge leakages } \\
\text { - } \quad \text { deor spatial resolution } \\
\text { presence of static forces } \\
\text { - } \begin{array}{l}\text { require to be embedded into the } \\
\text { machining structure }\end{array}\end{array}$ & [20] \\
\hline
\end{tabular}


As shown in Table 2, the amount of published papers about cutting force sensors per decade reflects a steadily increasing trend in research over the past few decades. In addition, the increase in magnitude of the publishing rate about cutting force sensors represents the rapid development and particular emphasis of the technology.

Table 2. Count of published papers about cutting force sensors from 1970.

\begin{tabular}{cccccc}
\hline Year & IEEE Library & ASME Digital Conllection & Compendex & Springer-Link & SPIE Digital Library \\
\hline $1970-1979$ & 8 & 0 & 8 & 22 & 2 \\
$1980-1989$ & 19 & 2 & 67 & 60 & 15 \\
$1990-1999$ & 94 & 17 & 185 & 129 & 76 \\
$2000-2009$ & 227 & 442 & 436 & 258 & 429 \\
$2010-$ present & 248 & 677 & 523 & 522 & 745 \\
\hline
\end{tabular}

\section{Cutting Force Sensing Techniques}

Multi-component cutting force sensing system can detect cutting forces along multiple axes by using various measurement techniques or principles. Some commonly studied techniques are based on theoretical models, current sensor, strain gauge, capacitive, optoelectronic, and piezoelectric methods. The selection of a proper technique for cutting force sensing system depends on the advantages and disadvantages of the techniques.

\subsection{Current-Sensor-Based Cutting Force Sensing Systems}

The first current-sensor-based cutting force measurement method was proposed by Taylor through assessing the current of the driving motors of the machine tool in the early years of the 20th century. Since then, all over the world, the number of reported initiatives with the goal of predicting cutting force through current and power measurement have increased dramatically. As shown in the Figure 1, current-sensor-based cutting force sensing approach predicts multi-component force through prediction models such as mathematical, analytical and experimental models with the current signals emitted by the tool machine drive motor [33-41].

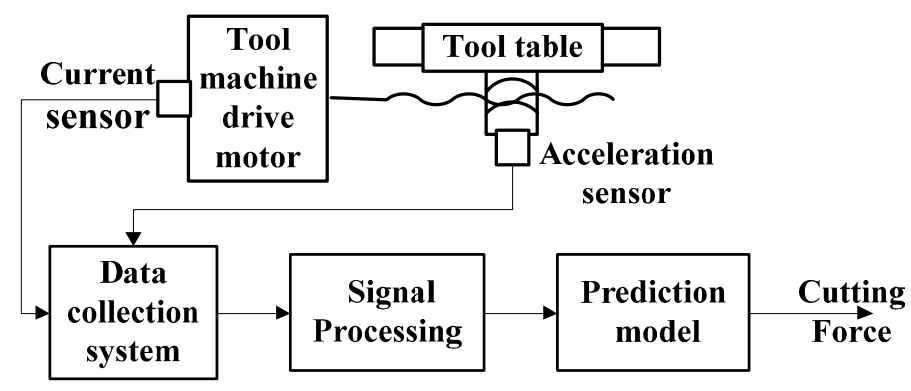

Figure 1. Schematic illustrations of current-sensor-based cutting force sensing technique.

Shin et al. [14] proposed a method for predicting cutting force in end-milling process with an acceleration sensor and Hall-effect current sensors. Stein et al. [42] proposed a dynamic lumped parameter model to characterize the current of a DC motor of a CNC machine tool, the electric current was used to calculate the cutting force and the forces associated with drive system components. Altintas $[43,44]$ described a model of a vertical milling machine feed drive control system to access the cutting force and predict the tool failures in milling, and the feasibility of the cutting force prediction approach based on armature current measurement was illustrated. Kim et al. [32,45], working with SENA Technologies, Inc. (San Jose, CA, USA), introduced a feasibility study for in-process multi-axis cutting force prediction approach based on an Artificial Neural Network (ANN) system with the input of current signals emitted by the tool machine drive motor, servo motor feed rates. The executed 
experiments show that the predicted cutting force obtained by the proposed approach agreed with the actual cutting force by comparison with method based on Kalman Filter (KF) disturbance observer. A four-layered ANN (an input layer, two hidden layers, and an output layer) can be used in the experiments. The input data comprised eight components, i.e., the current of two servo motors with one-step behind values, and the federation of two servo motors with one-step behind values. The output layer consists of one node indicating the cutting force. The performance of the proposed approach was influenced by the used training sample obtained under a specific cutting condition. Therefore, the generalization of the ANN needed to be considered further.

Li [46,47] discussed a three-axis cutting force measurement method by using inexpensive Hall-effect current sensors and models of the spindle and feed drive systems in a CNC turning center. An estimation algorithm based on neuro-fuzzy learning algorithm was proposed to estimate the tangential and axial cutting forces, and the axial cutting force was predicted based on the cutting mechanical model. The experimental results showed that proposed approach could measure multi-component cutting forces with an error of less than 25\%. Kim and Jeon [48] described an alternative cutting force sensor that measures the motor currents of the feed and spindle system via a 9-channel current sensor in preventing the usage of expensive dynamometers. Additionally, a mathematical model as a function of machining conditions was also formulated to forecast dynamic cutting forces. The maximum root-mean-square error between the measured and predicted cutting force was $25.99 \mathrm{~N}$ when the feed rate, spindle speed, and depth of cut were $60 \mathrm{mpm}, 1500 \mathrm{rpm}$ and $1.5 \mathrm{~mm}$ respectively. The main problem of this approach was that it had limited bandwidths and therefore cannot be used to measure dynamic cutting force.

A novel method to detect cutting force via command voltages drawn by electro-magnetic bearing was described by Auchet et al. [15], and the experimental results show that the calculated cutting forces are in good agreement with a commercial Kistler measurement system. The static accuracy and bandwidth of the proposed measuring system are within $8 \%$ and approximately $62 \mathrm{~Hz}$, respectively.

Essentially, the particular connection between the driving motor current and the cutting force of machining process is complicated. For example, the accelerating, decelerating and the friction force in the table and guide way will result in variation of the servo drive motor current. Therefore, it could be difficult to identify the actual relationship via general approaches, especially for machine tools with AC servo motors.

\subsection{Strain Gauge Cutting Force Sensing Systems}

Strain gauge sensing systems, has been widely used as direct measuring approaches to access cutting force in machining processes due to their advantages such as simple construction, high reliability, as well as high and adjustable resolution.

Santochi, Dini and Tantussi [49] described the first integrated strain gauge cutting force sensing system to monitor cutting force in turning processes. The strain gauges were mounted at specific positions on the tool with full bridge arrangement so as to maximize the system sensitivity. An infra-red data communications system was used to send the output of the bridge to the data acquisition system. Experimental results under different conditions demonstrated that the system repeatability and sensitivity were less than $\pm 3 \%$ F.S. and $0.24 \mathrm{mV} / \mathrm{N}$, respectively.

Yaldız, and Ünsaçar [30] described a turning dynamometer based on strain gauge and piezo-electric accelerometer to realize static and dynamic measurements of multi-axis cutting forces in turning operations. The proposed dynamometer included an elastic element in four octagonal rings shape, which was bonded with strain gauges that are connected into Wheatstone bridges. Feed force, thrust force and main cutting force are simultaneously detected with a maximum linearity error of $1.4 \%$ F.S. and a maximum coupling error of $0.92 \%$ F.S. Machining tests using different cutting parameters were performed, and the results indicated that the proposed strain gauge cutting force sensing system was dependable for turning, milling, and drilling operations, etc. 
For turning operations, Zhao et al. [50] developed a semi-conductive strain gauge-based cutting force sensing system that was integrated into the cutting tool to measure the two-axis cutting force. A novel elastic element with two mutually perpendicular rings that mounted to the cutting tool and the tool post was designed. This is advantageous to detect the cutting force with high sensitivity and improved natural frequency because it adopted the ingenious elastic element and MEMS fabrication method. The maximum sensitivity and natural frequency of the proposed system are $0.31 \mathrm{mV} / \mathrm{N}$ and $771 \mathrm{~Hz}$.

Zhao et al. [51] developed a tri-axial cutting force sensor with high-performance for turning processes. The sensitive element of the sensor was in the shape of two mutual-perpendicular octagonal rings. The static calibration experiment was carried out and the results show that the accuracy and the lowest natural frequency of the proposed sensor are $0.38 \%-0.83 \%$ and $1122 \mathrm{~Hz}$, respectively.

Recently, our team designed and developed a strain gauge cutting force sensing system [9] to measure six-axis cutting force in machining processes. With a novel elastic element (as shown in Figure 2) and an ingenious arrangement strategy of the mounted strain gauges on that, the sensing system was capable of detecting tangential, normal forces and the moments along three axes simultaneously. Benefitting from a Simulation-Driven Optimization method and an ANN-based decoupling algorithm, the system accessed the multi-axis cutting force with a maximum coupling error and nonlinearity error of $1.47 \%$ F.S. and $1.94 \%$ F.S., respectively.

Though the strain gauge cutting force sensing systems are capable of providing more accurate measurement, they have limitations like limited bandwidth, high cost, layout constraints, and fragility to overload [52-55].

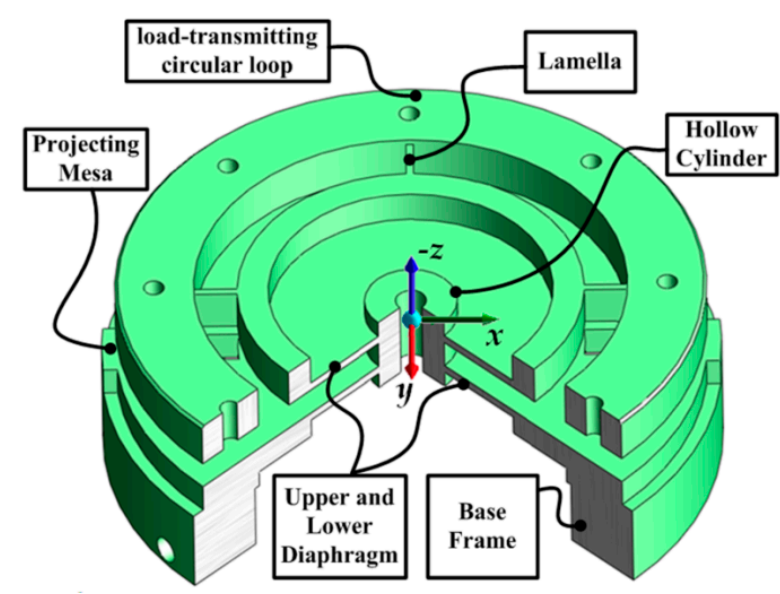

(a)

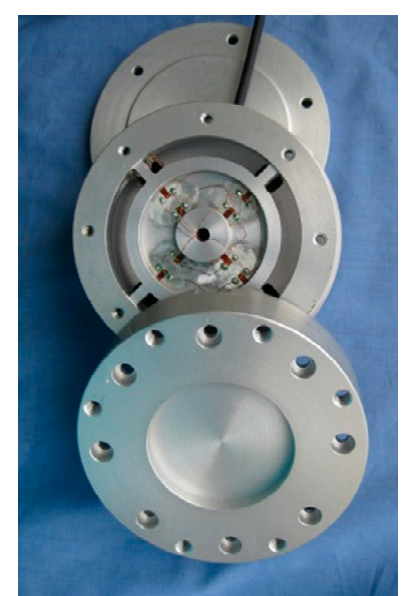

(b)

Figure 2. Six-axis strain gauge cutting force sensing system. (a) Sketch of the elastic element structure; (b) Fabricated prototype of the proposed sensor system.

\subsection{Capacitive Cutting Force Sensing Systems}

Capacitive cutting force sensing systems are one of the most sensitive approaches to access cutting forces and moments with $\mathrm{mN}$ even $\mathrm{pN}$ resolutions. Estimations show that more than $30 \%$ of the modern sensory systems employ capacitive measurement methods. The capacitive cutting force sensing system output can be acquired via switched-capacitor circuits, capacitive ac-bridges, and capacitance to frequency converters. Figure 3 shows a schematic drawing of a two-axial capacitive F/M sensor design. Transverse tri-plate differential comb is used to achieve a high sensitivity and linear input-output relationship [25]. 


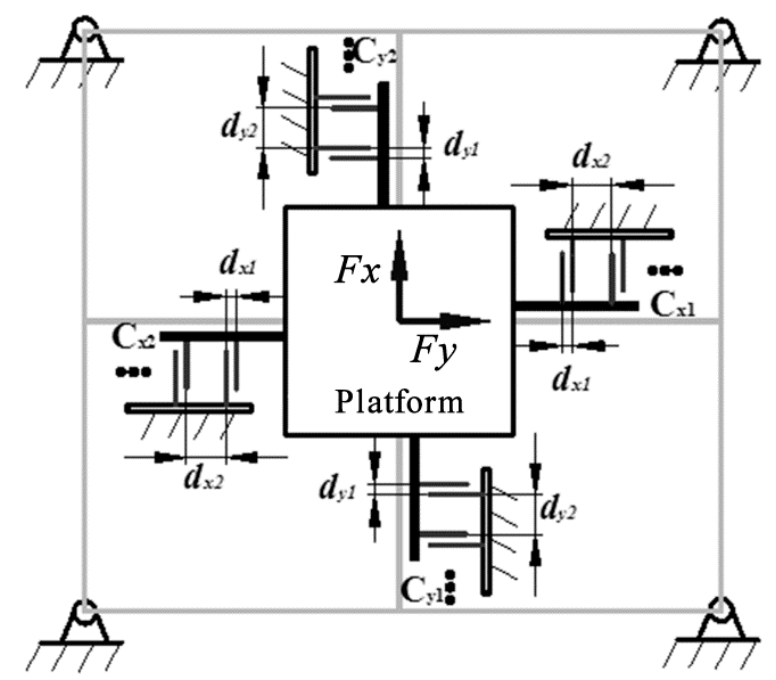

Figure 3. Schematic diagram of a two-axial capacitive force sensor.

The capacitances of the parallel plate capacitive sensor are given by [25]:

$$
\begin{aligned}
& C_{x 1}=k \frac{\varepsilon_{r} \varepsilon_{0} t l}{d_{x 1}}+k \frac{\varepsilon_{r} \varepsilon_{0} t l}{d_{x 2}}=\left(1+\frac{1}{n}\right) \frac{k \varepsilon_{r} \varepsilon_{0} t l}{d_{x 1}} \\
& C_{x 2}=k \frac{\varepsilon_{r} \varepsilon_{0} t l}{d_{x 1}}+k \frac{\varepsilon_{r} \varepsilon_{0} t l}{d_{x 2}}=\left(1+\frac{1}{n}\right) \frac{k \varepsilon_{r} \varepsilon_{0} t l}{d_{x 1}} \\
& C_{y 1}=k \frac{\varepsilon_{r} \varepsilon_{0} t l}{d_{y 1}}+k \frac{\varepsilon_{r} \varepsilon_{0} t l}{d_{y 2}}=\left(1+\frac{1}{n}\right) \frac{k \varepsilon_{r} \varepsilon_{0} t l}{d_{y 1}} \\
& C_{y 2}=k \frac{\varepsilon_{r} \varepsilon_{0} t l}{d_{y 1}}+k \frac{\varepsilon_{r} \varepsilon_{0} t l}{d_{y 2}}=\left(1+\frac{1}{n}\right) \frac{k \varepsilon_{r} \varepsilon_{0} t l}{d_{y 1}}
\end{aligned}
$$

where $k$ is the number of comb finger pairs, $t \times l$ is the common (overlapping) area of the comb fingers, $d_{x 1}, d_{x 2}$, and $d_{y 1}, d_{y 2}$ represent the initial gap width between electrodes (by initially setting $n d_{x 1}=d_{x 2}$, $\left.n d_{y 1}=d_{y 2}\right), \varepsilon_{r}$ and $\varepsilon_{0}$ denote the relative and vacuum permittivity, respectively.

For milling operations, Albrecht et al. [56] proposed an indirect cutting force sensing system based on capacitance displacement measurement. A high resolution capacitive sensor (C1-A/B, Lion Precision, Oakdale, MN, USA,) is mounted into the spindle to detect the gap variation between the spindle shaft and the sensor. After calibration with a commercial piezoelectric dynamometer (6255 B, Kistler, Winterthur, Switzerland), the gap variation is proportionally related to the applied cutting force. The static calibration experiment shows the system can measure the cutting force with satisfying linearity performance. However, the limited bandwidth of the system restricted by the structure of the spindle and machine tool is problematic. Benefitting from the proposed Kalman filter scheme based on the frequency response function of the capacitive sensor, the system bandwidth is expanded from $350 \mathrm{~Hz}$ to $1000 \mathrm{~Hz}$. For two-dimensional cutting force measurement, Mercedes-star and Cartesian arrangement strategies of capacitive sensors were introduced.

Kim et al. [21] developed a cutting force sensing system for milling operations by detecting spindle displacement with a cylindrical capacitive displacement sensor (CCDS). With the dynamic signals of the spindle tool system obtained from the CCDS, the multi-component dynamic cutting force was predicted. The dynamic cutting force estimation of the system has been shown to work in the laboratory and in the high speed cutting conditions on various machine tools. However, the quantitative analysis of the system performance has not yet been published.

Many of the latest researches and developments associated with cutting force sensing systems involve capacitive sensors that provide precise displacement measurement. Advantages of the systems 
are their wide frequency bandwidth, high resolution, noncontact measurement, and superior durability. Unfortunately, the capacitive cutting force sensing system suffers from some drawbacks such as complex integration into the machine tools, intrinsic temperature dependence, electrostatic edge effect, etc.

\subsection{Optoelectronic Cutting Force Sensing Systems}

Another common method to detect cutting force in machining relies on optoelectronic sensing. Manufacturing industries with harsh manufacturing environments may benefit from the use of multi-component optoelectronic cutting force sensing systems.

Fiber Bragg grating sensor, as the most promising optoelectronic force sensing system, have attracted considerable attentions due to their unique opto-electronic properties. Figure 4 shows a schematic drawing of optoelectronic cutting force sensing approach based on Fiber Bragg grating sensor through wavelength division multiplexing techniques.

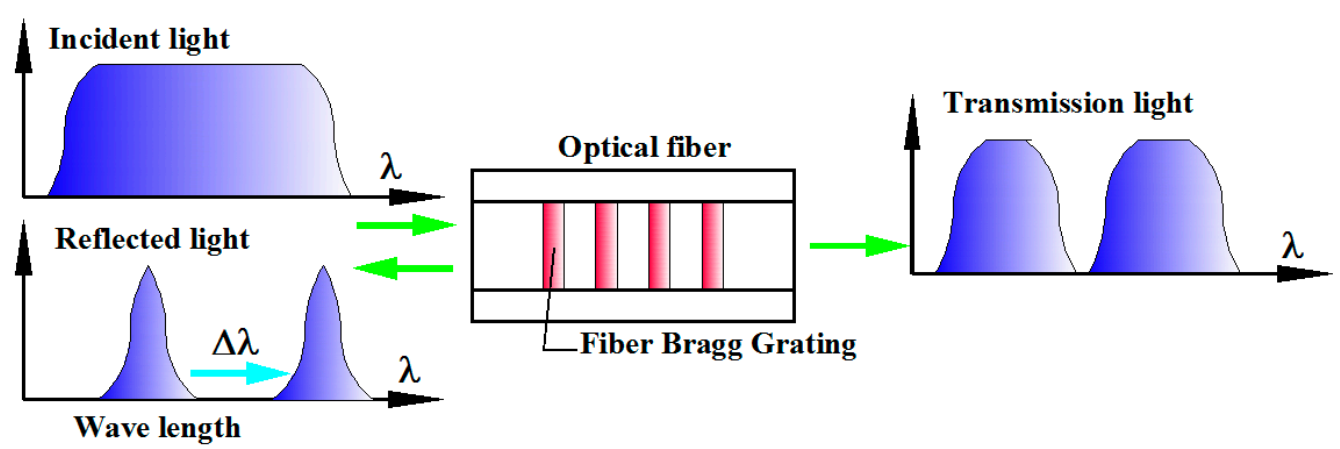

Figure 4. Schematic diagram of optoelectronic cutting force sensing approach based on Fiber Bragg grating sensor.

Liu et al. [31,57] published papers in which they investigated three perpendicular force measurement in milling operations based on Fiber Bragg grating sensor. An elastic body with four rings in annulus shape with pre-tightening device was designed, and the Fiber Bragg grating sensors was fixed on the elastic body. Verification experiments were performed and the results showed that the proposed approach could be adopted in milling and turning operations.

Jin et al. [23] described an approach for measuring cutting force with an optical fiber sensor. The calibration experiment and manufacturing test results demonstrate that the described approach possesses competitive advantage. The natural frequency, sensitivity and linearity of the system are $950 \mathrm{~Hz}, 2.51 \mathrm{mV} / \mathrm{N}$ and 1.2\% F.S., respectively.

For dynamic machining applications, Bartow, Calvert, and Bayly [58] proposed an optoelectronic micro machine tool motion sensing system based on Fiber Bragg Grating (FBG) sensors. The FBG sensors were mounted to the cutting tool surface, and precise evaluation of tool tip motion is performed by comparison with a piezoelectric accelerometer. Cutting texts in an actual lathe machining environment were carried out, and the results demonstrated the feasibility of the proposed system.

The competitive advantages of optoelectronic cutting force sensing systems are their wide measurement range, small volume, high reliability, low weight, greater adaptability, and anti-electromagnetic interference. Hence, optoelectronic cutting force sensing systems have attracted significant attention for applications of multi-component cutting force measurement.

\subsection{Piezoelectric Cutting Force Sensing Systems}

Most commercial cutting force sensing systems detecting the multi-axis cutting force in milling, turning, drilling or grinding based on piezoelectric method due to its wide dynamic range, high rangeability, good accuracy with finer resolution, high stiffness, smaller size, etc. [59-61]. As shown in 
the Figure 5, the piezoelectric cutting force sensing systems employ the piezoelectric effect of quartz crystal element to detect dynamic changes in cutting force.

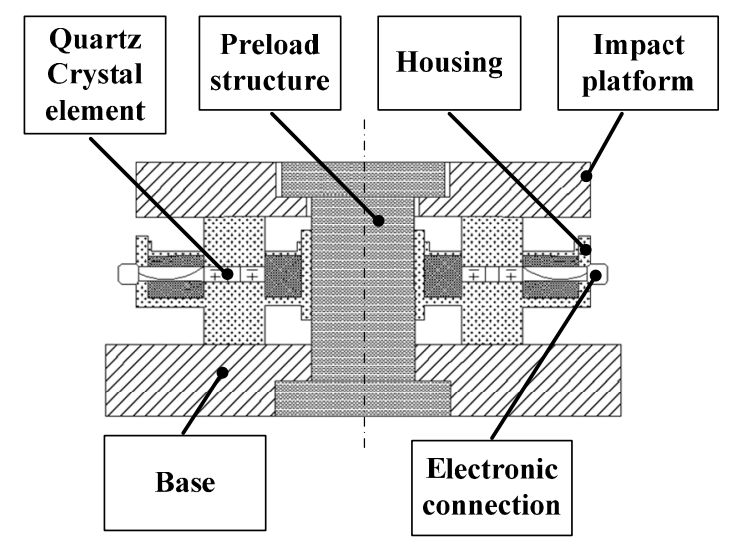

Figure 5. Schematic representation of piezoelectric cutting force sensor.

Totis et al. $[62,63]$ developed a three-component cutting force measurement based on piezoelectric cutting force sensing technology for turning operation. A commercial tri-axial piezoelectric force sensor (9251A, Kistler, Winterthur, Switzerland) was mounted into the prototype. Static calibration experiments and dynamic response tests of the developed prototype were carried out in a modern $\mathrm{CNC}$ lathe. The maximum relative error and static crosstalk disturbances are $6.6 \%$ and $3 \%$ respectively.

Park et al. $[26,64]$ presented several works on the design and development of cutting force sensing systems to monitor micro- or macro-machining processes. An integrated cutting force sensor system was designed and implemented to detect multi-axis cutting force by integrating piezoelectric force sensors into the spindle. The accuracy and frequency bandwidth of the cutting force sensing system is dramatically increased and that benefits from the proposed compensation method with sensing and the signal processing algorithm. The proposed system is used to optimize the feed rate, and monitor the chatter and tool breakage for milling operation. In another contribution, the authors developed a force sensing system to detect micro-cutting force based on a three-axis piezoelectric force sensor and a commercial accelerometer for micro-machining operations. The accelerometer was used to measure the vibration characteristics, and its signals were employed to increase the accuracy and bandwidth of the obtained multi-axis cutting force.

For on-line inspection of cutting geometry, Rao et al. [20] developed a piezoelectric cutting force sensing systems based on integrated piezoelectric dynamometer (209A02 of PCB Piezotronics Inc., Buffalo, NY, USA) with a resolution of $0.44 \mathrm{mN}$ and a sensitivity of $7 \mathrm{mV} / \mathrm{gm}$. The depth and width of cut is predicted by the proposed theoretical model with a relationship of geometry dimensions and the detected force signal. Experiments results represented that the proposed prediction approach was capable of measuring the cutting geometry with the maximum relative error of $10 \%$.

The piezoelectric cutting force sensing systems suffer from high cost, lag characteristics, mounting constraints, susceptible to the tool and workpiece dynamic characteristics. A further disadvantage of this cutting force measurement method is that the system is inflexible and needs recalibration due to the frequently changing workpieces.

\section{Application and Processing of the Acquired Cutting Force Information}

The prediction of cutting forces in machining is required for supervision of tool wear evolution or failure, access the generated heat, prediction of machined surface and workpiece accuracy, calibration of cutting force coefficients, analysis of material machinabilities, optimization of machining parameters, inspection of metal cutting chip formation, and detecting of chatter [65]. 


\subsection{Adaptive Control}

How to make a suitable selection of machining process parameters such as the cutting speed, feed rate, cut depth, and rake angles is a recurring problem for the manufacturing industry. Since the variation of cutting force is directly and specifically related to the cutting process conditions, it was realized that the cutting force is one of the most valuable variables to be controlled in the machining process. With the adaptive control of cutting force, the optimal machining parameters such as cutting speed, feed rate of the machining could be chosen. The optimal parameters ensure machining with high chip removal rate as well as prevention of excessive tool wear, breakage.

The need for dynamic detecting and real-time control of cutting force in machining raises various issues, as introduced by Karabulut [66]. Model-based control strategy of cutting force is ineffective due to the inaccurate mathematical model for machining systems. Lian et al. [67] proposed a model-free control strategy based on grey prediction fuzzy control law for constant cutting force in turning operations. To evaluate control performance of the introduced control strategy, an old lathe turning system was converted with an inverter, an encoder, an AC servo motor, a load cell and a compatible PC. The experiment results show that the converted lathe turning system using the grey prediction fuzzy controller is able to achieve the control of constant cutting force with improved performance than using traditional fuzzy controller. A further advantage of this cutting force control method is that the chattering of the cutting tool was significantly suppressed.

Zuperl et al. [68,69] proposed a neural control strategy, cooperating with CNC, to optimize the machining process with constant cutting force in end milling. The control strategy ensures continuous optimization of machining parameters by adaptively adjusting feed rate according to the particular situations. A commercial piezoelectric cutting force sensor (9255, Kistler, Winterthur, Switzerland) was used to simultaneously measure the three-component cutting force. With the introduced control strategy, the cutting force in machining was maintained to be consistent with the reference value, and then the maximum metal removal rate was obtained to significantly reduce manufacturing cost and machining time by approximately $24 \%$. The stability and robustness of the proposed feed-forward neural control scheme (FFNCS) were confirmed by the simulation and machining experiments.

Despite growing interest from both research institutes and commercial companies in designing and developing reliable, robust cutting force control strategy for manufacturing progresses in different cutting conditions, the utilization of these strategies in commercial CNC machine tool control systems has been minimal. However, modern machine tools with open architecture controllers are the key enabler for the progressive realization of adaptive cutting force control to increase manufacturing efficiency, avoid excessive cutting tool wear, and prevent potential tool breakage.

\subsection{Predicting and Evaluating Real-Time Tool Wear and Tool Breakage}

Multi-component cutting force sensing systems have gradually become known as the most reliable indicators of important cutting action information, and have been widely used to predict and evaluate cutting tool conditions such as wear and breakage of the cutting tool [70-74].

Intelligent or reliable evaluation and prediction of cutting tool wear condition based on cutting force sensing system is capable of preserving the cutting tools, CNC machine tools servo drive systems, and manufacture components in metal cutting operations. Li et al. [47] proposed an intelligent monitoring system for cutting tool wear condition based on a fuzzy classification method and a current-sensor-based cutting force sensing system. Cutting force in turning processes was obtained via a neuro-fuzzy approach with the feed rate and feed motor current. Cutting tool wear condition was estimated with the fuzzy classification method. The experimental results demonstrated that the accurate prediction of the cutting tool could be achieved over a range of cutting conditions. A further advantage of this estimation approach is that the system is inexpensive due to the current-sensor-based cutting force measurement approach. Additionally, a number of investigators have used current-sensor-based cutting force estimation approach for the analysis of cutting tool wear in different cutting operations [75-77]. 
Balsamo et al. [78] proposed a multi-sensor monitoring system to identify Catastrophic Tool Failure (CTF). The system consists of a commercial tri-axial force sensor (9017B, Kistler, Winterthur, Switzerland) mounted on the clamps and an acoustic emission sensor (8152B, Kistler, Winterthur, Switzerland). A reliable detection methodology for cutting tool breakage based on the combined information from the sensors was developed for turning operation.

For machining operations with some stainless steel materials of hard machinability, evaluation of the cutting tool wear becomes even more significant and complicated. Selvaraj et al. [79] analyzed the influence of machining cutting speed and feed rate on cutting force, surface roughness of manufactured part, and cutting tool wear in turning progress of nitrogen alloyed duplex stainless steel. They disclosed that cutting force and surface roughness were strongly affected by the feed rate parameter, while the cutting tool wear condition was primarily affected by the cutting speed. The Taguchi optimization methodology was used to optimize cutting parameters in turning progresses when machining duplex stainless steel.

In a similar effort, Rizal et al. [80] estimated cutting force by multi-component strain gauge sensing systems integrated on the cutting tool holder, and proposed a cutting tool wear monitoring approach based on I-kaz 2D and I-kaz ${ }^{\mathrm{TM}}$ methods. The relationship between the cutting force signal and the progression of cutting tool wear has been derived from the turning machining texts. It has been found that cutting force shows an increasing rate, following the rising of flank wear evolution. In addition, the feed cutting force increased more massively than the main cutting force due to the progression of the cutting tool flank wear.

For tool wear detection and fault diagnosis in metal cutting processes, Huang et al. [81] developed an inexpensive tool fault detection and diagnosis approach based on an observer model. A commercial cutting force dynamometer was mounted into the machining center to evaluate tool wear, and a camera system was used to estimate the amount of tool wear. Several cutting processes under different cutting conditions were carried out and the results showed that the proposed approach was effective.

Multi-component cutting force has a great impact on cutting tool wear and failures. Consequently, multi-component cutting force sensing systems are emphasized as critical component in the modern manufacturing systems due to technical and economic reasons. To minimize the excessive tool wear and improve the tool life, different sensing systems and monitoring methods based on Artificial Intelligence $(\mathrm{AI})$ can be utilized for monitoring and controlling the cutting tool wear condition to prevent additional costs. Among the various sensing and monitoring systems, cutting force sensing systems are the most efficient. However, the system performance still needs to be improved to be applied into the actual automatic manufacturing systems.

\subsection{Detecting and Controlling Chatter}

Cutting tool chatter, also called self-excited cutting tool vibrations, results in negative effects such as rough surface finish, poor workpiece accuracy, unwanted noise, reduced product quality and industry productivity. Generally, chatter in metal cutting operations originates from the dynamic interaction effect between structural and cutting dynamics [82,83]. Among the numerous detection and control strategies for chatter in automatic manufacturing systems introduced in the literature, methods based on dynamic cutting force re drawing more and more attention for their intrinsic relationship with dynamic systems.

Tlusty et al. were among the first to propose studying machine tool chatter in 1958 [84,85]. Since then, a number of research teams have carried out work on detecting and controlling chatter to improve the quality and productivity in the manufacturing industry [86-89].

For the cutting chatter stability lobes prediction method, Peng et al. [90] proposed a novel prediction approach based on simulation model of cutting force and support vector machine (SVM) theory. Multi-component cutting force along $x$ - and $y$-axis was detected with a commercial cutting force sensing system (9257 B, Kistler, Winterthur, Switzerland) and used to recognize cutting chatter. Feature extraction of multi-component cutting force signals was performed based on wavelet energy 
entropy theory. Experimental tests carried out on a CNC machining center, and the results demonstrate that the prediction based on SVM can identify the cutting chatter with an accuracy rate of $98.333 \%$.

The traditional manufacturing industry always employs conservative cutting conditions to prevent cutting chatter, which results in low productivity and high cost. Dynamic cutting force was widely estimated to predict the cutting chatter reliably and accurately. However, very few common or industrial chatter detection and control systems based on multi-component cutting force measurement are available. In addition, methods for detecting and controlling cutting chatter always need to be amended according to the specific cutting tool, workpiece, tool path, cutting conditions, machine tools, etc.

\subsection{Other Applications with Multi-Component Cutting Force Information}

In recent years, emerging areas of modern manufacturing industry have resulted from the application of multi-component cutting force information [91]. For example, Risbood et al. [92] proposed a prediction method based on neural networks for surface finish and dimensional deviation with multi-component cutting force and vibration sensing system. Ramesh et al. [93] analyzed error sources induced by cutting-force associated with geometric and fixture dependent errors. Accordingly, error compensation or elimination methods for every kind of error were proposed. Segreto et al. [94] proposed a multiple sensor monitoring system that consists of a cutting force sensor and an acceleration sensor to estimate the Ni-Ti alloy workpiece machinability in turning operation. The correlation between the pattern feature vectors from the sensorial data and the process quality was investigated with a pattern recognition method based on an adaptive Neuro-fuzzy inference system. The experimental results showed that the proposed method significantly decreased the average Root Mean Square Error (RMSE) to 0.012. Due to the advantages of multi-component cutting force sensing systems, they have been shown to be suitable in more various applications.

\section{Discussion and Conclusions}

Regardless of the fact that much research and development has been carried out in recent decades, significant work is urgently needed before accurate, reliable, and cost effective multi-component cutting force sensing systems will be commonly adopted in modern machine tools. Over the past decade, our team has designed and developed various multi-component force sensing systems aiming at force measurement in robotic manipulation and unmanned machine operations. For the future directions and challenges of multi-component cutting force sensing system, the following conclusions and observations can be reached based on our review:

- Multi-component cutting force sensing techniques: the emergency of new force sensing technology such as vision-based and fiber Bragg grating sensors-based sensing techniques, MEMS-based sensing systems, optoelectronic based devices, and film based sensors will make it possible to measure the multi-component cutting force with higher performance. Specifically, piezoelectric cutting force sensing system is ideally suited for the detection of the multi-component cutting force due to its high frequency response and high dynamic range. Other sensing techniques can be used in different machining applications. For example, vision-based force sensing technology for micro-machining operations.

- Frequency bandwidth: the strain gauge cutting force sensing system is restricted to be applied in the high speed machining operations due to its limited frequency bandwidth. Dynamic behavior of the machining system is various with the machine tool type, cutting conditions, workpiece and cutting tools. Therefore, multi-component cutting force sensing system with superior dynamic performance can achieve stable long-term frequency behavior, and will be used as a common sensing system for different machining operations.

- From single component to multiple components: more and more cutting force sensing systems for modern machine tools can measure the force with multiple components. Right now the commonly 
available systems always have two or three force components, and it will be remarkable to upgrade the sensing system with three additional torque components.

- Overload protection: to avoid fatal damage due to excessive cutting force, overload protection in both mechanism and software keeps drawing attention in the design and development of multi-component cutting force sensing systems. Additionally, overload protection is capable of preventing accuracy variation of the machining operations under excessive cutting conditions. However, no mature overload protection for multi-component cutting force sensing system or unmanned machining operations is available until now.

- Stiffer cutting force sensing systems: the stiffness of the machining system depends on the component with minimum stiffness. For direct cutting force measurement approaches, the cutting force sensing system is always the weakest component in the force-flux flow of the machining system. Therefore, the modern machine tools can benefit from cutting force sensing system with higher stiffness. Simulation-driven design, multi-objectives optimization, and optimization exploration could be used to design and develop stiffer cutting force sensing systems.

- Multi-sensor data fusion system: other than cutting force sensing systems, other kinds of sensors such as accelerometers, dimensional, proximity, vibration and acoustic emission sensors and their signals could be used to gather more valuable and accurate information. Feature extraction processes and decision making methods are helpful to obtain useful features and improve the efficiency of the inspection.

- Modern machine tools and smart machining: intelligence level of the manufacturing process could be heightened by using adaptive cutting force control, on-line monitoring real-time tool wear and tool breakage, error compensation, etc.

Acknowledgments: This work was supported in part by the National Nature Science Foundation of China (NSFC 61673163), Hunan provincial natural science foundation of China (2016JJ3045), Changsha science and technology program (k1501009-11), and State Key Laboratory of Advanced Design and Manufacturing for Vehicle Body (31565006).

Author Contributions: Q.L. completed the literature review, D.Z. provided guidance and discussion in theory, W.W. and K.Z. interpreted the data and offered particular details, Q.L. and W.W. co-wrote the manuscript.

Conflicts of Interest: The authors declare no conflict of interest.

\section{References}

1. Tlusty, J.; Andrews, G.C. A critical review of sensors for unmanned machining. CIRP Ann. Manuf. Technol. 1983, 32, 563-572. [CrossRef]

2. Totis, G.; Adams, O.; Sortino, M.; Veselovac, D.; Klocke, F. Development of an innovative plate dynamometer for advanced milling and drilling applications. Measurement 2014, 49, 164-181. [CrossRef]

3. Elbestawi, M.A.; Dumitrescu, M. Tool condition monitoring in machining-neural networks. Inf. Technol. Balanced Manuf. Syst. 2006, 220, 5-16.

4. Matsushima, K.; Bertok, P.; Sata, T. In process detection of tool breakage by monitoring the spindle current of a machine tool. Meas. Control Batch Manuf. 1982, 1, 145-154.

5. Penedo, F.; Haber, R.E.; Gajate, A. Hybrid incremental modeling based on least squares and Fuzzy-NN for monitoring tool wear in turning processes. IEEE Trans. Ind. Inform. 2012, 8, 811-818. [CrossRef]

6. Zhou, J.H.; Pang, C.K.; Lewis, F.L. Intelligent diagnosis and prognosis of tool wear using dominant feature identification. IEEE Trans. Ind. Inform. 2009, 5, 454-464. [CrossRef]

7. Constantinides, N.; Bennett, S. An investigation of methods for the on-line estimation of tool wear. Int. J. Mach. Tool. Manuf. 1987, 27, 225-237. [CrossRef]

8. Huo, D.; Choong, Z.J.; Shi, Y.; Hedley, J.; Zhao, Y. Diamond micro-milling of lithium niobate for sensing applications. J. Micromech. Microeng. 2016, 26,1-10. [CrossRef]

9. Liang, Q.; Zhang, D.; Coppola, G.; Mao, J.; Sun, W.; Wang, Y.; Ge, Y. Design and Analysis of a Sensor System for Cutting Force Measurement in Machining Processes. Sensors 2016, 16. [CrossRef] [PubMed]

10. Segreto, T.; Simeone, A.; Teti, R. Multiple sensor monitoring in nickel alloy turning for tool wear assessment via sensor fusion. Procedia CIRP 2013, 12, 85-90. [CrossRef] 
11. Zuperl, U.; Irgolic, T.; Cus, F. Surface Roughness Monitoring in Cutting Force Control System. Proc. Manuf. Syst. 2015, 10, 59-64.

12. Chen, Y.L.; Shimizu, Y.; Cai, Y.; Wang, S.; Ito, S.; Ju, B.F.; Gao, W. Self-evaluation of the cutting edge contour of a microdiamond tool with a force sensor integrated fast tool servo on an ultra-precision lathe. Int. J. Adv. Manuf. Technol. 2015, 77, 2257-2267. [CrossRef]

13. Li, Y.; Zhao, Y.; Fei, J.; Zhao, Y.; Li, X.; Gao, Y. Development of a Tri-Axial Cutting Force Sensor for the Milling Process. Sensors 2016, 16. [CrossRef] [PubMed]

14. Shin, B.C.; Ha, S.J.; Cho, M.W.; Seo, T.I.; Yoon, G.S.; Heo, Y.M. Indirect cutting force measurement in the micro end-milling process based on frequency analysis of sensor signals. J. Mech. Sci. Technol. 2010, 24, 165-168. [CrossRef]

15. Auchet, S.; Chevrier, P.; Lacour, M.; Lipinski, P. A new method of cutting force measurement based on command voltages of active electro-magnetic bearings. Int. J. Mach. Tool. Manuf. 2004, 44, 1441-1449. [CrossRef]

16. Tuysuz, O.; Altintas, Y.; Feng, H.Y. Prediction of cutting forces in three and five-axis ball-end milling with tool indentation effect. Int. J. Mach. Tools Manuf. 2013, 66, 66-81. [CrossRef]

17. Tsai, C.; Liao, Y. Cutting force prediction in ball-end milling with inclined feed by means of geometrical analysis. Int. J. Adv. Manuf. Technol. 2010, 46, 529-541. [CrossRef]

18. Fussell, B.K.; Jerard, R.B.; Hemmett, J.G. Modeling of cutting geometry and forces for 5-axis sculptured surface machining. Comput. Aided Des. 2003, 35, 333-346. [CrossRef]

19. Ferry, W.B.; Altintas, Y. Virtual five-axis flank milling of jet engine impellers-Part I: Mechanics of five-axis flank milling. J. Manuf. Sci. Eng. 2008, 130. [CrossRef]

20. Rao, B.C.; Gao, R.X.; Friedrich, C.R. Integrated force measurement for on-line cutting geometry inspection. IEEE Trans. Instrum. Meas. 1995, 44, 977-980. [CrossRef]

21. Kim, J.H.; Chang, H.K.; Han, D.C.; Jang, D.Y.; Oh, S.I. Cutting force estimation by measuring spindle displacement in milling process. CIRP Ann. Manuf. Technol. 2005, 54, 67-70. [CrossRef]

22. Kim, J.D.; Kim, D.S. Development of a combined-type tool dynamometer with a piezo-film accelerometer for an ultra-precision lathe. J. Mater. Process. Technol. 1997, 71, 360-366. [CrossRef]

23. Jin, W.L.; Venuvinod, P.K.; Wang, X. An optical fibre sensor based cutting force measuring device. Int. J. Mach. Tools Manuf. 1995, 35, 877-883. [CrossRef]

24. Liang, Q.; Zhang, D.; Ge, Y.; Song, Q. A novel miniature four-dimensional force/torque sensor with overload protection mechanism. IEEE Sens. J. 2009, 9, 1741-1747. [CrossRef]

25. Liang, Q.; Zhang, D.; Coppola, G.; Wang, Y.; Sun, W.; Ge, Y. Multi-Dimensional MEMS/Micro Sensor for Force and Moment Sensing: A Review. IEEE Sens. J. 2014, 14, 2643-2657. [CrossRef]

26. Park, S.S. High Frequency Bandwidth Cutting Force Measurements in Milling Using the Spindle Integrated Force Sensor System. Ph.D. Thesis, University of British Columbia, Vancouver, BC, Canada, 2003.

27. Jantunen, E. A summary of methods applied to tool condition monitoring in drilling. Int. J. Mach. Tools Manuf. 2002, 42, 997-1010. [CrossRef]

28. Bayo, E.; Stubbe, J.R. Six-axis force sensor evaluation and a new type of optimal frame truss design for robotic applications. J. Robot. Syst. 1989, 6, 191-208. [CrossRef]

29. Svinin, M.M.; Uchiyama, M. Optimal geometric structures of force/torque sensors. Int. J. Robot. Res. 1995, 14, 560-573. [CrossRef]

30. Yaldız, S.; Ünsaçar, F. A dynamometer design for measurement the cutting forces on turning. Measurement 2006, 39, 80-89. [CrossRef]

31. Liu, M.; Zhou, Z.; Tao, X.; Tan, Y. A dynamometer design and analysis for measurement the cutting forces on turning based on optical fiber Bragg Grating sensor. In Proceedings of the 2012 10th World Congress on Intelligent Control and Automation (WCICA), Beijing, China, 6-8 July 2012.

32. Kim, T.Y.; Kim, J. Adaptive cutting force control for a machining center by using indirect cutting force measurements. Int. J. Mach. Tools Manuf. 1996, 36, 925-937. [CrossRef]

33. Martellotti, M.E. An analysis of the milling process. Trans. ASME 1941, 63, 677-700.

34. Tlusty, J.; Macneil, P. Dynamics of cutting forces in end milling. Ann. CIRP 1975, 24, 21-25.

35. Kline, W.A.; DeVor, R.E.; Lindberg, J.R. The prediction of cutting forces in end milling with application to cornering cuts. Int. J. Mach. Tool Des. Res. 1982, 22, 7-22. [CrossRef] 
36. Euan, I.G.; Ozturk, E.; Sims, N.D. Modeling Static and Dynamic Cutting Forces and Vibrations for Inserted Ceramic Milling Tools. Procedia CIRP 2013, 8, 564-569. [CrossRef]

37. Schmitz, T.L.; Smith, K.S. Machining Dynamics: Frequency Response to Improved Productivity; Springer: Berlin, Germany, 2008.

38. Teitenberg, M.; Bayoumi, A.E.; Yucessan, G. Tool wear modeling through analytical mechanistic model of milling process. Wear 1992, 154, 287-304. [CrossRef]

39. Choudhury, S.K.; Rath, S. In-process tool wear estimation in milling using cutting force model. J. Mater. Process. Technol. 2000, 99, 113-119. [CrossRef]

40. Zaman, M.T.; Kumar, A.S.; Rahman, M.; Sreeram, S. A three-dimensional analytical cutting force model for micro end milling operation. Int. J. Mach. Tools Manuf. 2006, 46, 353-366. [CrossRef]

41. Bao, W.Y.; Tansel, I. Modeling micro end milling operations, Part I: Analytical cutting force model. Int. J. Mach. Tool Manuf. 2000, 40, 2155-2173. [CrossRef]

42. Stein, J.L.; Colvin, D.; Clever, G.; Wang, C.-H. Evaluation of DC servo machine tool feed drives as force sensors. Trans. ASME J. Dyn. Syst. Meas. Control 1986, 108, 279-288. [CrossRef]

43. Altintas, Y. Prediction of cutting forces and tool breakage in milling from feed drive current measurements. Trans. ASME J. Eng. Ind. 1992, 114, 386-392. [CrossRef]

44. Altintas, Y.; Dong, C.L. Design and analysis of a modular CNC system for machining control and monitoring. In Modeling of Machine Tools: Accuracy, Dynamics, and Control; American Society of Mechanical Engineers (ASME): New York, NY, USA, 1993; Volume 45, pp. 199-208.

45. Kim, T.Y.; Woo, J.; Shin, D.; Kim, J. Indirect cutting force measurement in multi-axis simultaneous NC milling processes. Int. J. Mach. Tools Manuf. 1999, 39, 1717-1731. [CrossRef]

46. $\mathrm{Li}, \mathrm{X}$. Development of current sensor for cutting force measurement in turning. IEEE Trans. Instrum. Meas. 2005, 54, 289-296. [CrossRef]

47. Li, X.; Li, H.X.; Guan, X.P.; Du, R. Fuzzy estimation of feed-cutting force from current measurement-a case study on intelligent tool wear condition monitoring. IEEE Trans. Syst. Man Cybern. Part C Appl. Rev. 2004, 34, 506-512. [CrossRef]

48. Kim, D.; Jeon, D. Fuzzy-logic control of cutting forces in CNC milling processes using motor currents as indirect force sensors. Precis. Eng. 2011, 35, 143-152. [CrossRef]

49. Santochi, M.; Dini, G.; Tantussi, G.; Beghini, M. A sensor-integrated tool for cutting force monitoring. CIRP Ann. Manuf. Technol. 1997, 46, 49-52. [CrossRef]

50. Zhao, Y.; Zhao, Y.; Wang, C.; Liang, S.; Cheng, R.; Qin, Y.; Hu, T. Design and development of a cutting force sensor based on semi-conductive strain gauge. Sens. Actuators A Phys. 2016, 237, 119-127. [CrossRef]

51. Zhao, Y.; Zhao, Y.; Liang, S.; Zhou, G. A High Performance Sensor for Triaxial Cutting Force Measurement in Turning. Sensors 2015, 15, 7969-7984. [CrossRef] [PubMed]

52. Şeker, U.; Kurt, A.; Ciftci, I. Design and construction of a dynamometer for measurement of cutting forces during machining with linear motion. Mater. Des. 2002, 23, 355-360. [CrossRef]

53. Jain, R.; Rathore, J.K.; Gorana, V.K. Design, Development and Testing of a Three Component Lathe Tool Dynamometer Using Resistance Strain Gauges. In CAD/CAM, Robotics and Factories of the Future; Springer: New Delhi, India, 2016; pp. 13-21.

54. Pathri, B.P.; Garg, A.K.; Unune, D.R.; Mali, H.S.; Dhami, S.S.; Nagar, R. Design and Fabrication of a Strain Gauge Type 3-axis Milling Tool Dynamometer: Fabrication and Testing. Int. J. Mater. Form. Mach. Process. 2016, 3, 1-15. [CrossRef]

55. Uddin, M.S.; Songyi, D. On the design and analysis of an octagonal-ellipse ring based cutting force measuring transducer. Measurement 2016, 90, 168-177. [CrossRef]

56. Albrecht, A.; Park, S.S.; Altintas, Y.; Pritschow, G. High frequency bandwidth cutting force measurement in milling using capacitance displacement sensors. Int. J. Mach. Tools Manuf. 2005, 45, 993-1008. [CrossRef]

57. Liu, M.; Zhang, Z.; Zhou, Z.; Peng, S.; Tan, Y. A new method based on Fiber Bragg grating sensor for the milling force measurement. Mechatronics 2015, 31, 22-29. [CrossRef]

58. Bartow, M.J.; Calvert, S.G.; Bayly, P.V. Fiber Bragg grating sensors for dynamic machining applications. In Proceedings of the Sixth Pacific Northwest Fiber Optic Sensor Workshop, Troutdale, OR, USA, 14-15 May 2003.

59. Tahir, N.H.M.; Muhammad, R.; Ghani, J.A.; Nuawi, M.Z.; Haron, C.H.C. Monitoring the flank wear using piezoelectric of rotating tool of main cutting force in end milling. J. Teknol. 2016, 78. [CrossRef] 
60. Zhu, X.; Lin, B.; Liu, L.; Luan, Y. Power Transfer Performance and Cutting Force Effects of Contactless Energy Transfer System for Rotary Ultrasonic Grinding. IEEE Trans. Ind. Electron. 2016, 63, 2785-2795. [CrossRef]

61. Hübner, H.B.; de Souza, A.J. Evaluation of Machining Forces in Asymmetrical Face Milling of Cast Iron DIN GGG50. In Key Engineering Materials; Trans Tech Publications: Pfaffikon, Switzerland, 2015; Volume 656, pp. 271-276.

62. Totis, G.; Sortino, M. Development of a modular dynamometer for triaxial cutting force measurement in turning. Int. J. Mach. Tools Manuf. 2011, 51, 34-42. [CrossRef]

63. Totis, G.; Wirtz, G.; Sortino, M.; Veselovac, D.; Kuljanic, E.; Klocke, F. Development of a dynamometer for measuring individual cutting edge forces in face milling. Mech. Syst. Signal Process. 2010, 24, 1844-1857. [CrossRef]

64. Chae, J.; Park, S.S. High frequency bandwidth measurements of micro cutting forces. Int. J. Mach. Tools Manuf. 2007, 47, 1433-1441. [CrossRef]

65. Castro, L.R.; Viéville, P.; Lipinski, P. Correction of dynamic effects on force measurements made with piezoelectric dynamometers. Int. J. Mach. Tools Manuf. 2006, 46, 1707-1715. [CrossRef]

66. Karabulut, S.. Optimization of surface roughness and cutting force during $\mathrm{AA} 7039 / \mathrm{Al}_{2} \mathrm{O}_{3}$ metal matrix composites milling using neural networks and Taguchi method. Measurement 2015, 66, 139-149. [CrossRef]

67. Lian, R.J.; Lin, B.F.; Huang, J.H. A grey prediction fuzzy controller for constant cutting force in turning. Int. J. Mach. Tools Manuf. 2005, 45, 1047-1056. [CrossRef]

68. Zuperl, U.; Cus, F.; Reibenschuh, M. Neural control strategy of constant cutting force system in end milling. Robot. Comput. Integr. Manuf. 2011, 27, 485-493. [CrossRef]

69. Zuperl, U.; Cus, F.; Milfelner, M. Fuzzy control strategy for an adaptive force control in end-milling. J. Mater. Process. Technol. 2005, 164, 1472-1478. [CrossRef]

70. Kurada, S.; Bradley, C. A review of machine vision sensors for tool condition monitoring. Comput. Ind. 1997, 34, 55-72. [CrossRef]

71. Siddhpura, A.; Paurobally, R. A review of flank wear prediction methods for tool condition monitoring in a turning process. Int. J. Adv. Manuf. Technol. 2013, 65, 371-393. [CrossRef]

72. Afazov, S.M.; Zdebski, D.; Ratchev, S.M.; Segal, J.; Liu, S. Effects of micro-milling conditions on the cutting forces and process stability. J. Mater. Process. Technol. 2013, 213, 671-684. [CrossRef]

73. Liu, T.I.; Jolley, B. Tool condition monitoring (TCM) using neural networks. Int. J. Adv. Manuf. Technol. 2015, 78, 1999-2007. [CrossRef]

74. Jemielniak, K.; Szafarczyk, M. Detection of cutting edge breakage in turning. CIRP Ann. Manuf. Technol. 1992, 41, 97-100. [CrossRef]

75. Li, X.; Djordjevich, A.; Venuvinod, P.K. Current-sensor-based feed cutting force intelligent estimation and tool wear condition monitoring. IEEE Trans. Ind. Electron. 2000, 47, 697-702. [CrossRef]

76. Salgado, D.R.; Alonso, F.J. An approach based on current and sound signals for in-process tool wear monitoring. Int. J. Mach. Tools Manuf. 2007, 47, 2140-2152. [CrossRef]

77. Stavropoulos, P.; Papacharalampopoulos, A.; Vasiliadis, E.; Chryssolouris, G. Tool wear predictability estimation in milling based on multi-sensorial data. Int. J. Adv. Manuf. Technol. 2016, 82, 509-521. [CrossRef]

78. Balsamo, V.; Caggiano, A.; Jemielniak, K.; Kossakowska, J.; Nejman, M.; Teti, R. Multi Sensor Signal Processing for Catastrophic Tool Failure Detection in Turning. Procedia CIRP 2016, 41, 939-944. [CrossRef]

79. Selvaraj, D.P.; Chandramohan, P.; Mohanraj, M. Optimization of surface roughness, cutting force and tool wear of nitrogen alloyed duplex stainless steel in a dry turning process using Taguchi method. Measurement 2014, 49, 205-215. [CrossRef]

80. Rizal, M.; Ghani, J.A.; Nuawi, M.Z.; Haron, C.H.C. The Application of I-kaz TM-based Method for Tool Wear Monitoring Using Cutting Force Signal. Procedia Eng. 2013, 68, 461-468. [CrossRef]

81. Huang, S.N.; Tan, K.K.; Wong, Y.S.; De Silva, C.W.; Goh, H.L.; Tan, W.W. Tool wear detection and fault diagnosis based on cutting force monitoring. Int. J. Mach. Tools Manuf. 2007, 47, 444-451. [CrossRef]

82. Kim, S.J.; Lee, H.U.; Cho, D.W. Prediction of chatter in NC machining based on a dynamic cutting force model for ball end milling. Int. J. Mach. Tools Manuf. 2007, 47, 1827-1838. [CrossRef]

83. Munoa, J.; Beudaert, X.; Dombovari, Z.; Altintas, Y.; Budak, E.; Brecher, C.; Stepan, G. Chatter suppression techniques in metal cutting. CIRP Ann. Manuf. Technol. 2016, 65, 785-808. [CrossRef]

84. Tobias, S.A.; Fishwick, W. Theory of regenerative machine tool chatter. Engineer 1958, 205, 199-203. 
85. Tlusty, J.; Polacek, M. The stability of machine tools against self-excited vibrations in machining. ASME Int. Res. Prod. Eng. 1963, 1, 465-474.

86. Li, H.; Li, X. Modelling and simulation of chatter in milling using a predictive force model. Int. J. Mach. Tools Manuf. 2000, 40, 2047-2071. [CrossRef]

87. Budak, E.; Altintas, Y. Analytical prediction of chatter stability in milling-Part I: General formulation. J. Dyn. Syst. Meas. Control 1998, 120, 22-30. [CrossRef]

88. Budak, E.; Altintas, Y. Analytical prediction of chatter stability in milling-Part II: Application of the general formulation to common milling systems. J. Dyn. Syst. Meas. Control 1998, 120, 31-36. [CrossRef]

89. Grossi, N.; Sallese, L.; Scippa, A.; Campatelli, G. Chatter stability prediction in milling using speed-varying cutting force coefficients. Procedia CIRP 2014, 14, 170-175. [CrossRef]

90. Peng, C.; Wang, L.; Liao, T.W. A new method for the prediction of chatter stability lobes based on dynamic cutting force simulation model and support vector machine. J. Sound Vib. 2015, 354, 118-131. [CrossRef]

91. Byrne, G.; O'Donnell, G.E. An integrated force sensor solution for process monitoring of drilling operations. CIRP Ann. Manuf. Technol. 2007, 56, 89-92. [CrossRef]

92. Risbood, K.A.; Dixit, U.S.; Sahasrabudhe, A.D. Prediction of surface roughness and dimensional deviation by measuring cutting forces and vibrations in turning process. J. Mater. Process. Technol. 2003, 132, 203-214. [CrossRef]

93. Ramesh, R.; Mannan, M.A.; Poo, A.N. Error compensation in machine tools-a review: Part I: Geometric, cutting-force induced and fixture-dependent errors. Int. J. Mach. Tools Manuf. 2000, 40, 1235-1256. [CrossRef]

94. Segreto, T.; Caggiano, A.; Teti, R. Neuro-fuzzy System Implementation in Multiple Sensor Monitoring for Ni-Ti Alloy Machinability Evaluation. Procedia CIRP 2015, 37, 193-198. [CrossRef]

(C) 2016 by the authors; licensee MDPI, Basel, Switzerland. This article is an open access article distributed under the terms and conditions of the Creative Commons Attribution (CC-BY) license (http:/ / creativecommons.org/licenses/by/4.0/). 